\title{
iFRAMES DESIGN IN HEALTH SECTOR BLUD: ASSET AND INVENTORY SYSTEM
}

\author{
Satrio Wicaksono Prakoso ${ }^{1 *}$ and Machmudin Eka Prasetya ${ }^{2}$ \\ ${ }^{1,2}$ Universitas Indonesia, Depok, Indonesia
}

\begin{abstract}
This research aims to design an information system to record assets and inventories at DKI Jakarta Regional Public Service Agency (BLUD). This study is based on the findings from Examination Report (LHP) issued by the Indonesian Supreme Audit Institution (BPK RI) which states that there are quite a few problems about assets at BLUD (BPK RI, 2017). This research is expected to answer research questions about how to design the system of assets and inventories needed by BLUD to assist the process of internal control and asset management. This study uses the Framework for the Application of Systems Thinking (FAST) as a method for systems development popularized by Whitten and Bentley (2007). This study uses a case study approach with the triangulation method, where the qualitative data as primary data by conducting interviews and observations. Unit of analysis in this study is the BLUD responsible for asset management. Currently, the existing asset information systems only record fixed assets and not connected to the financial reporting system. Assets and inventories information need to move manually by re-inputting the value to prepare financial statements. The result of this research is a design of asset information system to enhance internal control.
\end{abstract}

Keywords: Assets, Information Systems, Internal Control Systems

\section{INTRODUCTION}

Recording assets is one of the essential factors for an agency to carry out its operations. Good asset management can improve organizational performance in achieving its objectives effectively and efficiently; therefore special attention needs to be given. This is because in general, assets have a price that is not cheap and has a long useful life.

According to Ministry of Home Affairs Regulation (2007), Regional Public Service Agency (BLUD) reports its assets to the Regional Government in the form of a Goods Inventory Card Report $(K I B)$. However, based on initial interview, the process of assets reporting at the $B L U D$ was still done manually using the Microsoft Excel program and then forwarded to the Regional Government as an asset report. The control function is still very low if it uses a procedure like this, because it has the potential to cause asset problems. It has been noted that since 1980, the DKI Provincial Government has lost assets of an area of 19.7 hectares (Tempo, 2017). One of the leading causes is due to lack of attention to these assets. The assets were released due to losing the court dispute, where most of the troubled assets involved the private sector. Generally, the government cannot show evidence in the form of original certificates when facing disputes in court (Tempo, 2017).

The Examination Report (LHP) issued by Indonesian Supreme Audit Institution (BPK RI) on May 29, 2017, on the 2016 Jakarta Provincial Government Financial Report stated that there were quite a lot of problems regarding assets at the BLUD (BPK RI, 2017). There are land assets that have been transferred to other Regional Working Unit (SKPD), but the land assets are still recorded in the previous SKPD. As for more recorded land assets (abolition of land assets) that are not supported by adequate deletion documents amounting to 1.4 billion IDR (BPK RI, 2017). Also, there is a calculation of depreciation of assets that have not been charged as much as 216 billion IDR. The findings show that the current recording system is still not optimal which can lead to inconsistencies in recording assets and inventories. DKI Provincial Government

* Corresponding author. Email address : satrioowp@gmail.com 
seeks to maintain assets to reduce the risk of loss of assets together with the Regional Asset Management Agency (BPAD).

The asset identification process needs to be done to identify the year of procurement, the source of funds, code of goods, the location of the asset, etc. The process of recording and managing assets at the $B L U D$ can be better by using an integrated system that can provide asset report output automatically. This system will also be expected to assist in the process of making a Room Inventory Card (KIR) automatically by identifying the position of the asset. So that no assets are missed in making KIR. The asset identification process can be done by providing a barcode on each asset to find out the details of the asset, for example by installing a QR code on an asset when registering a new asset.

Adlar (2014), in his research, state that assets need to be given special attention, and it can be seen by reviewing the internal control standard of an organization. One suggestion he proposed to improve internal control is to develop a system for recording assets. Zain (2008) stated in his research, the failure of implementation of a system can be minimized using the Framework for the Application of Systems Thinking (FAST) methodology since it has several steps to analyze problems and implementation process.

From the problems that occur at the BLUD regarding the asset and inventory recording system, it is expected that this study can answer research questions about how the asset and inventory system design is needed by the BLUD using FAST method. The system design is supposed to be able to assist the management and internal control processes. The solutions to offer are in the form of information inventory system design that have been adjusted to the needs of the $B L U D$ so that the process of managing assets and inventories becomes more organized and structured.

\section{LITERATURE STUDY}

\subsection{Previous Study and Theory}

Previously, a study conducted by Adlar (2014) shows on how internal assets of fixed assets were carried out at 1st Echelon Organizational Unit of Indonesian National Armed Forces Headquarters. This study mentions that there are several reasons why assets need to be given special attention, including because assets generally have a long useful life and are considered as investments, relatively high asset prices, and the acquisition of assets is intended for long-term use. The case study in this research is in the form of a review of the internal control of assets in the aspects of acquisition, deletion, inventory, security, and maintenance of the 1st Echelon Organizational Unit of Indonesian National Armed Forces. The results of the study state that internal control of assets on aspects of elimination, inventory, and safeguarding assets have not met the standards. One suggestion proposed in this study is to develop a system for recording assets so that they can be matched with the physical conditions of assets in the field.

This study uses contingency theory related to effective leadership and management as a theoretical basis. Fiedler (1974) states that contingency theory explains how the leadership style and situation matches. According to this theory, there is no best way to manage an organization optimally, because there are internal and external factors that can affect the organization. So the organization needs to make adjustments continuously. Regarding asset management, the threat of internal factors can take the form of weak internal control of assets. While the risk of external factors is in the form of a land dispute claim. Based on this, a mechanism is needed that can help the process of managing assets adequately to reduce the threat of weak internal controls.

\subsection{Regional Public Service Agency (BLUD)}

Government Accounting Standards Statement (PSAP) Number 13 states that the Public Service Agency $(B L U)$ is an institution that is in the central or regional government that aims to provide services to the public without regard to profits. The accountability that needs to be reported by the $B L U$ is in the form of a Financial Report which is divided into Budget Realization Reports, Changes to More Budget Balance 
Reports, Balance Sheet Reports, Operational Reports, Cash Flow Reports, Changes in Equity Reports, and Notes to Financial Reports. The Balance Sheet Report describes the financial position of the entity reporting assets, liabilities, and equity. So that based on PSAP Number 13, the recording and reporting of assets and inventories are in the Balance Sheet Report.

At the local government level, assets are commonly referred to as local property, namely all goods purchased using the Regional Budget (APBD). Bookkeeping is carried out on a local property under the provisions of the Ministry of Home Affairs Number 1 of 2008, in which the process of recording goods to a list of user goods, goods inventory cards, and a list of goods belonging to the region. Bookkeeping of inventory is done to find out the wealth owned by the local government. Bookkeeping carried out includes information about the location, type and type, amount, price, size, year of purchase, and others.

\subsection{System Development}

Companies use information systems to help operational business processes in the form of easy access to information for users of information. Generally, the system consists of several small sub-systems that have their duties to support large systems (Romney, 2015). The primary function of an information system includes input, process, and, output. Changes made to a sub-system need to be considered the impact on other sub-systems. Romney (2015) argues that information is a collection of data that is processed and arranged in such a way that has a meaning and helps in making decisions. Decision making will be better with the amount and quality of information possessed. But too much information can lead to poor decision making, commonly referred to as information overload.

One method used to develop the system is the Framework for the Application of Systems Thinking (FAST) method (Bentley \& Whitten, 2007). The FAST method consists of eight stages carried out sequentially, starting from the scope definition phase, problem analysis, needs analysis, logical design, decision analysis, physical design and integration, construction and testing, and the last is installation and delivery (Bentley \& Whitten, 2007). The following is an explanation of each step in the FAST framework.

\section{Scope Definition}

This stage is done to find out how significant the problem is and the scope of the issue includes the magnitude and limits of the unit of analysis. The result of the scope definition stage is a problem statement. The problem statement framework can be described using the PIECES Framework developed by Wetherbe. PIECES Framework includes aspects of performance, information, economics, control or security, efficiency, and services. PIECES is used to classify problems to determine the needs needed to correct problems.

Apart from categorizing problems, it is also necessary to identify obstacles such as budget limits, deadlines, resources, government policies and regulations, and technology. Based on these considerations, an initial scope is needed so that the results of the first phase are two, namely the problem statement and the initial scope. All results obtained from the first stage are summarized in the Statement of Work in the form of contracts or agreements to develop an information system.

2. Problem Analysis

Studying existing systems or processes are done to do problem analysis as a basis for reference for improvement. The results of this stage are in the form of a System Improvement Objectives, namely in the kind of desired business criteria for the system being evaluated. Also, it is necessary to analyze whether the benefits received will exceed the costs that need to be spent to correct specific problems that exist in the system. So by following this process, a priority sequence of problems can be determined that needs to be adjusted.

3. Requirement Analysis 
This stage is done to find out the needs needed by the user of the system. Collecting and analyzing data used for sorting these needs to describe the actual field conditions. Data acquisition can be made by several methods, including analysis of documents, questionnaires, interviews, and observations. Business Requirements Statement summarized all results for the needs of the system. This stage cannot be skipped in the system development process. Generally, the failure of the implementation of a new system or application is caused by the needs needed by the user not provided by the system.

\section{Logical Design}

This stage translates business needs identified previously into system models. In practice, the requirements analysis stage is often carried out together with a logical design, because when a need has been identified and documented, the model can be directly created. System analysis referred to the first four stages in the FAST method.

5. Decision Analysis

At this stage, an analysis of several infrastructure options will be used to implement the system. This decision can be in the form of making your system by yourself or using other parties, how many systems need to be automated, and other things. The goal at this stage is to identify candidates for technical solutions, analyze possibilities for the candidate, and recommend the system to be designed.

6. Physical Design and Integration

After determining the software and hardware that will be used, the necessary needs are transformed into the physical design as a guideline in carrying out system design. The physical design pays attention to the technology used to build systems, for example, physical database design specifications, business process specifications and software designs, and physical user interface specifications. Physical design divided into two types, namely design by specification and design by prototyping. In practice, both applied together.

7. Construction and Testing

Then the construction and testing of the design will be carried out. This process is carried out to determine whether the system design that has made was following the level as predicted by the user system and produces the appropriate output. When the testing phase has completed, the system is ready for installation and delivery.

8. Installation and Delivery

The last step of this method is to install a new system. In order for the transition to the old to new system to run smoothly, it is necessary to make a conversion plan. There are two types of system conversions. The first is to replace the old system to a whole new system at a certain time. Second is to gradually replace the old system into a new system. The second method is a safer and more convenient way for system users compared to how to replace the entire system at one time. This stage also includes training programs for system users, so it is expected that the use of the new system will be maximized according to the design.

At the stage of logical design in system development, two types of modeling need to do, namely, process modeling and data modeling. Process modeling uses the process flow on the needs of business activities as a guideline for designing an effective software system. Process modeling can be described using a flowchart in the form of a Data Flow Diagram (DFD) or Use Case Diagram. The use of diagrams like this intended as a medium of communication between non-technical users and system design designers to prevent misunderstandings (Bentley \& Whitten, 2007).

DFD is a diagram that describes the flow of data in an organization, including data sources, data flow, transformation processes, and data storage (Romney, 2015 p. 50). There are four essential elements used in DFD, namely the source and destination of data, data flow, transformation process, and data storage. The source and purpose of the data described by an entity that sends or receives data. Entity is represented by a box symbol on DFD. Data flow is the movement of data that occurs in the process, storage, source, and purpose. Data flow is symbolized by an arrow image on DFD so 
that data movement can be seen. The transformation process describes the processing that occurs in a DFD. The process represented by a circle symbol on DFD. Generally, the data processing process produces new data to be used at a later stage. Data storage is where the data stored. In DFD, it is not physically described as a data storage medium. Data storage symbols represented by two horizontal lines with the name of the file written in the line. The symbol of notation in DFD shown in Figure 1. While Use Case Modeling according to Whitten (2007) is a diagram that describes the function of the system with the perspective of external users. By using this diagram, it will be seen how the authority allowed by each user on the system (p. 246).

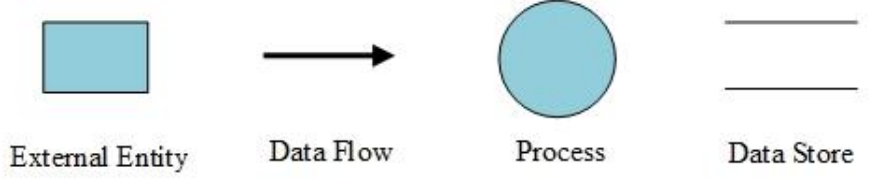

Figure 1 Data Flow Diagram Symbols

\section{RESEARCH METHODOLOGY}

The methodology carried out in this study is a case study approach. Stake (2006) explains that case studies used as research methods that study the uniqueness of the characteristics in the examined case, where the cause of a phenomenon is the main reason for the research itself. So that to review a case study research requires a lot of information and in-depth analysis related to matters relating to the phenomenon. This study uses a case study approach to propose a design on an asset and inventory information system in the BLUD that will be integrated with the Integrated Financial Reporting and Management Information System (iFRAMES).

This study wants to find out what the asset recording system needed by $B L U D$ is to reduce the risks of asset loss by analyzing how the $B L U D$ currently records assets and factors that can cause the loss of an asset.

\subsection{Triangulation Method}

In answering a research question, three approaches can be used depending on the information needs to be needed, namely quantitative, qualitative, and a combination of the two. The combination of the two approaches is also called the triangulation method. Some benefits of using triangulation methods, including making researchers more confident about the results of their research, and can demand the creativity of researchers to obtain data to produce more and more in-depth information (Jick, 1979).

The approach in this study uses a combination of qualitative and quantitative methods, where quantitative data used as supporting data. This process can be referred to as a concurrent triangulation method, which is that the interaction between the two methods is only limited to the process of data collection, but the processing results in the interpretation process complement each other (Morse, 1991). The process of data collection will use several sources to obtain information that supports research. In this study, the type of data will be more dominated by qualitative data than quantitative. The emphasized focus is on a system that can help $B L U D$ operational activities well. This information obtained from qualitative data through respondents who understand the flow of a system and the users of the system itself. Quantitative data is only a complement to qualitative data. The nature of this study is within triangulation, which used more than one way to obtain qualitative data. Qualitative data obtained by conducting interviews with several parties and document reviews to find out the requirements for a system of recording assets and inventories in the BLUD.

\subsection{Unit of Analysis}

According to Trochim (2006), the first step to determine how data will be analyzed is to define the unit of analysis first. The unit of analysis is the object studied in the study. Analysis units can take the form of individuals, groups, artifacts, geographical units or social interactions. The unit analysis perspective can also vary, for example, individuals as families, individuals as communities, individuals as 
communities, and others. The analysis in this study is a single case with multi embedded data, meaning that the data source comes from more than one sub-unit of analysis (Yin, 2003). This research conducted at DKI Jakarta Regional Public Service Agency $(B L U D)$, especially in the sub-facilities and infrastructure section which is responsible for asset management.

\subsection{Data Analysis}

All data from the results of collection by interview or document review will not provide information without being processed first. Data analysis is a process of sorting data and mapping it into a pattern or category (Moleong, 2002). In the analysis of qualitative data, data are not described with numerical values but categorized by their nature.

The document review carried out is based on the LHP prepared by the BPK RI in each period that contains asset information. In the $B P K R I$ findings, there will be an examination result in which the notes report record conditions and field conditions are not the same. The reason for the difference in the recording will be the question of the topic of discussion during the interview. Processing data is done using direct interpretation techniques.

\section{RESULTS}

\subsection{Scope Definition and Problem Analysis}

Using the FAST method, the first step to develop a system is scope definition. Determination of the scope of the problems and limitations on the unit of analysis can be done by applying the PIECES Framework developed by Wetherbe (Whitten, 2007). PIECES Framework is an analysis that looks at performance, information, economics, control, efficiency, and service. The results of the PIECES Framework analysis carried out in the form of a Statement of Work. The identified problems come from three types of classification, namely problems, opportunities, and directives. Problems are issues that are present in the system, so they need to take corrective actions. Opportunity is a potential development in the current system. Directives are requests by users for functions or features that can be facilitated by the system. In this case, for the convenience of all three classification groups, this will be called a problem. After making a list of problems that exist in the current conditions, an analysis of each problem will be carried out. Analysis of the problems carried out in the form of impacts that will arise and solutions to correct the problem. In this case, scope definition and problem analysis were carried out on the asset and inventory system in the $B L U D$. The following Table 1 is the identification of problems and impacts.

Table 1 List of Problems, Impacts, and Solutions

\begin{tabular}{|c|c|c|}
\hline Problem & Impact & Solution \\
\hline $\begin{array}{l}\text { There are no tools to } \\
\text { measure the response time of } \\
\text { goods management related } \\
\text { to supply demand and } \\
\text { distribution }\end{array}$ & $\begin{array}{l}\text { It is difficult to carry out } \\
\text { response time analysis } \\
\text { which can be used as an } \\
\text { evaluation material to be } \\
\text { able to make continuous } \\
\text { improvements }\end{array}$ & $\begin{array}{l}\text { A system that has a log } \\
\text { timestamp request and } \\
\text { inventory distribution is } \\
\text { needed so that response time } \\
\text { analysis can be performed }\end{array}$ \\
\hline $\begin{array}{l}\text { Update of asset and } \\
\text { inventory data presented in } \\
\text { the Financial Report } \\
\text { manually given }\end{array}$ & $\begin{array}{l}\text { The time needed to prepare } \\
\text { financial statements is } \\
\text { longer and is prone to errors }\end{array}$ & $\begin{array}{l}\text { Withdrawal of asset and } \\
\text { inventory data can be done } \\
\text { automatically and integrated }\end{array}$ \\
\hline $\begin{array}{l}\text { There is no notification } \\
\text { mechanism for the lease } \\
\text { period }\end{array}$ & $\begin{array}{l}\text { There is a potential for lack } \\
\text { of revenue from the use of } \\
\text { assets by third parties }\end{array}$ & $\begin{array}{l}\text { Created rental notification } \\
\text { feature in the Information } \\
\text { System }\end{array}$ \\
\hline
\end{tabular}


There are no features that ensure the authenticity of the document

Vulnerable to document forgery

The process of making Record of Transfer (BAST) requires typing timeconsuming specification data

There are no full features to produce regional property reports and financial reports
Specifications data are prone to errors and need to check repeatedly

The system has the potential to produce reports that are less accurate, inconsistent, and unreliable

Creating digital signature
features so rat
confidentiality and data
integrity is guaranteed

Made an Information System that can withdraw data item specifications for making $B A S T$

Made an Information System that can provide features for preparing reports of regional property and financial statements

\subsection{Requirement Analysis}

After problems were identified, then next step is to analyze the needs that need to be provided by the system to deal with existing issues. The first problem is regarding information systems that have not been able to help to prepare Regional Property Reports and Financial Reports fully. This was also stated by BPK RI on the 2016 LHP which indicates that the current information system has not been able to provide a reconciliation process between the realization of capital expenditure and changes in $K I B$. The opportunities that can be taken to apply to the design of information systems, namely in the form of notification of the rental period and response time. Previously, the LHP noted that there was a shortage of revenue from third-party assets in the form of leasing land to lease ATM rooms. If the system can detect the lease period, the system will be able to provide a notification that the lease period will expire. Thus, the lack of revenue from the use of assets can be minimized. Response time can be used as a variable for performance measurement. This response time will record the period needed for all steps starting from the request to the distribution of goods or supplies. The response time is expected to be an easier evaluation of performance.

Based on these needs, the system must be able to provide the following functions:

1. The system can provide asset and inventory data to the financial reporting system automatically and integrated.

2. The system can record information regarding demand and distribution related to inventory.

3. The system can provide logs related to inventory distribution so that that response time can be known as a medium for work evaluation.

4. The system can provide approval mechanisms related to the receipt / distribution of assets or inventory.

\subsection{Design of Integrated Information System Structure}

This study designed an information system for recording assets and inventory which is one module of an integrated system. The integrated system proposed by this study is called the Integrated Financial Reporting and Management Information System or abbreviate as iFRAMES. iFRAMES consist of four main modules, where each module has its function. The four modules are Asset \& Inventory Information System (ASSIST), Budgeting, Monitoring and Evaluation Information System (BORDERS), Accounting \& Reporting Information System (ARISE), and Procurement Information System. The focus of this research is to discuss the functions that exist at ASSIST. The structure of iFRAMES illustrated in Figure 2. 


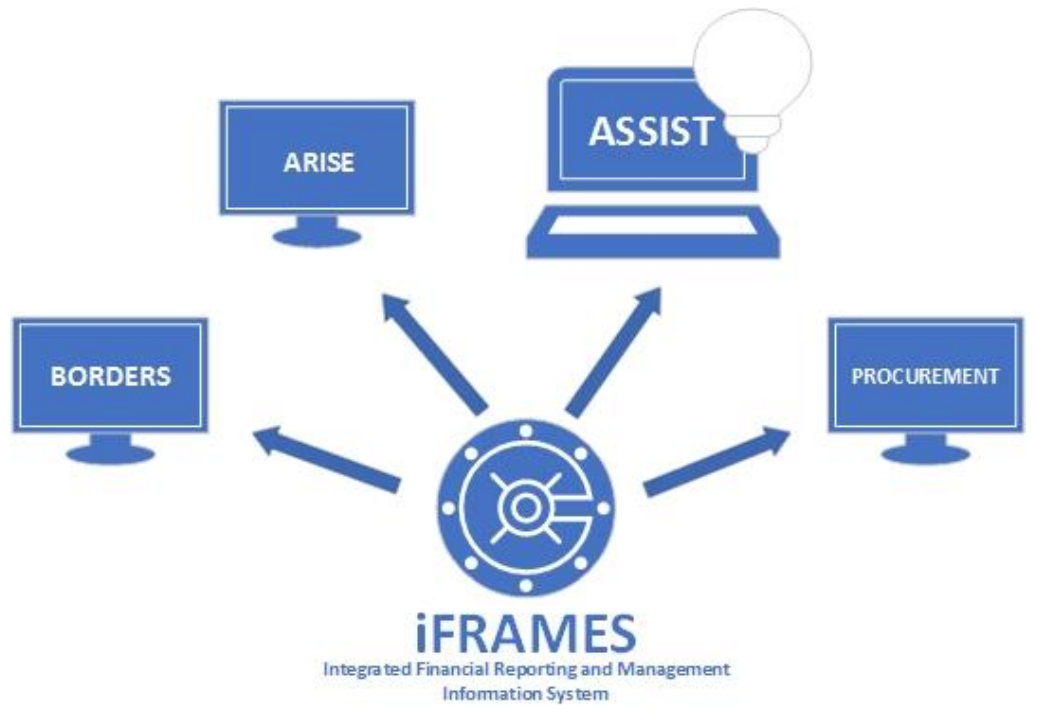

Figure 2 iFRAMES Intergrated System Structure

\subsection{Logical Design (Data Flow Diagram)}

Context diagram describes the interaction between the system and external entities that provide input or output to each other in the form of data flow. External entities can be present as a person, units within an organization, units outside the organization or another information system. Figure 3 shows the design of the context diagram made from the results of data.

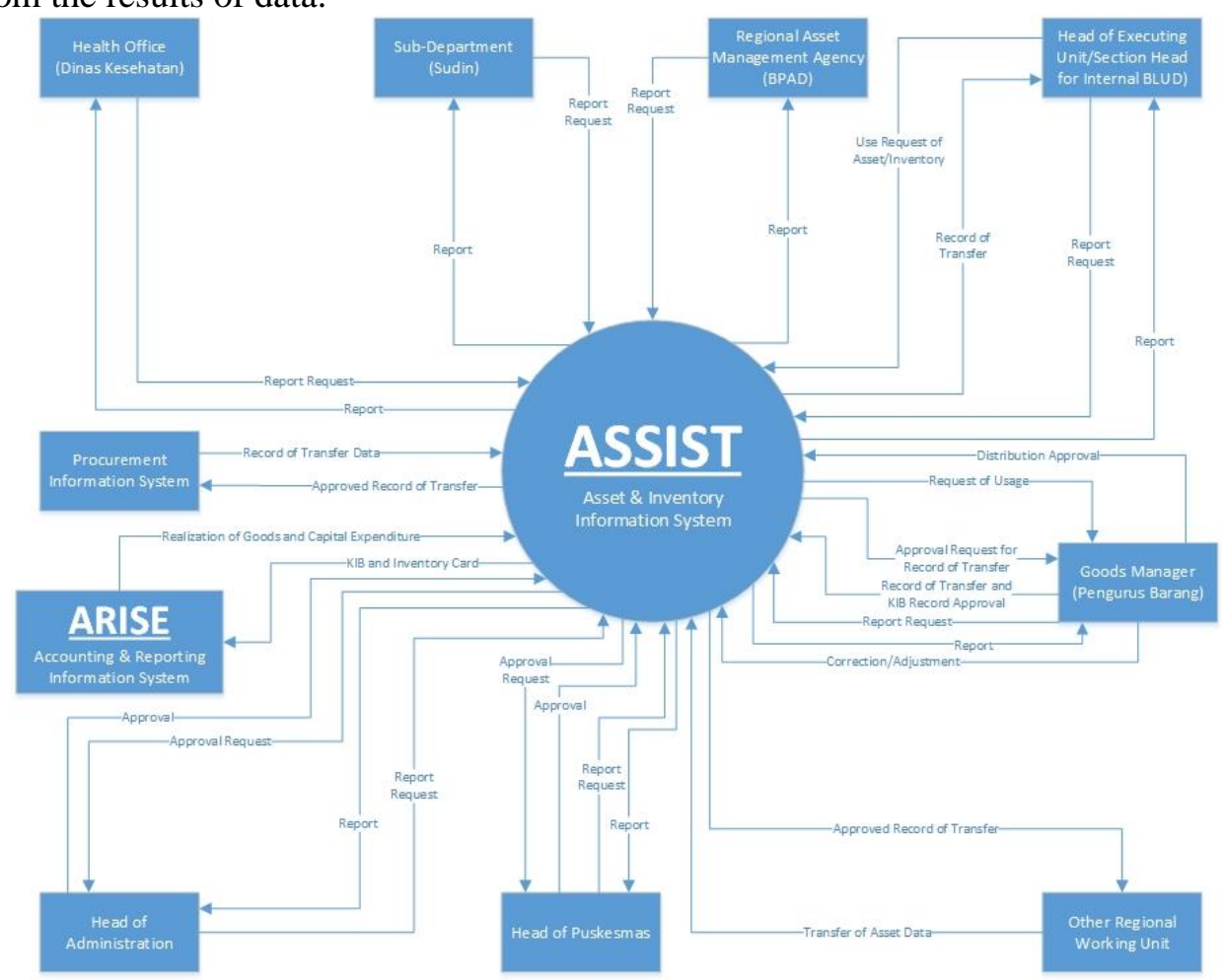

Figure 3 Context Diagram of ASSIST

\section{DISCUSSION}

The asset and inventory recording system, ASSIST, as seen in Figure 3 is part of the primary system that integrates with other systems. It is expected that with the proposed design will optimize the system of recording existing assets and inventories. The interview results state that the current system is not optimal, because the asset 
system is only used as an information database. Also there is no system that records inventory. When the Financial Report wants to be compiled, then information about assets and inventories is moved manually by printing asset information at that time through the system, and then re-inputting when preparing financial statements. By carrying out system integration, this stage can be eliminated because ASSIST will immediately update continuously related to $K I B$ and Inventory Card information, including forwarding the info to ARISE.

In developing the system, there are scope definition stages to find out the problem, the scope of the problem, and the limits on the unit of analysis. One of the tools used in analyzing scope definition is to use the PIECES Framework. PIECES analysis Framework is carried out using contingency theory considerations, namely by paying attention to internal and external factors of the organization. Internal factors can be in the form of internal control over the management of assets and inventory, as an example of the process of acquisition, deletion, inventory, security, and maintenance. External factors can be in the form of land disputes or loss of potential income on assets leased to outside parties. It is expected that with the proposed design of this system, the process of managing assets and inventories can run better to reduce threats, both from inside and outside.

The first flow of the ASSIST starts from the input obtained from the Procurement Information System, which is in the form of Record of Transfer Document from Committee of Procurement Result Examination (PPHP) with Goods Manager (PB). Procurement Information System is a system that handles all matters related to procurement of goods. The $B A S T$ document from $P P H P$ to $P B$ data will be forwarded to $P B$ by the system for $B A S T$ approval requests. When $P B$ confirms the approval, the system will provide a notification to the Head of the Administration and the Head of the Puskesmas for the approval application to record goods or supplies into the Goods Inventory Card Report (KIB) or Inventory Card. If the registration application approved by the Head of the Administration and the Head of the Puskesmas, the system can record the $K I B$ and the Inventory Card. Additionally, the system also forwards $K I B$ and Inventory Card information to the Accounting \& Reporting Information System (ARISE). ARISE itself will provide information in the form of data on the realization of goods and capital expenditures to ASSIST. The data can be used as a comparison with assets and capital data recorded on ASSIST. So that if there is a difference in recording, it will be immediately visible and immediately corrections and adjustments can be made by the management of the goods.

The application for the use of assets or inventory starts with Head of Executing Unit (Kasatpel)/Section Head for internal BLUD. Kasatpel will send request of use via ASSIST and the system will notify the goods manager for the use approval process. When the request for use has been confirmed by the $P B$, the item may be distributed, and $B A S T$ will be given to the user who made the request. In addition to the application for the use of goods, the transfer of goods between other Regional Working Unit $(S K P D)$ is also done via the system. Through ASSIST, another SKPD will provide data on the transfer of goods to the recipient to be confirmed. Goods or inventory data will not move before the recipient party confirms receipt. This is done so that there is no difference in recording between the two parties, for example, assets that are equally recorded in two SKPD or together are not recorded.

Other functions provided by ASSIST are for reporting. Requests for asset and inventory reports can come from various types of entities, including Goods Manager $(P B)$, Health Office, Sub-Department, Regional Asset Management Agency (BPAD), Head of Executing Unit, Head of Puskesmas, and Head of Administration. Reports of assets and inventories issued must go through the approval stage by the party 
responsible first, including the Goods Manager and Head of the Administration or Head of the Puskesmas.

\section{CONCLUSION}

The scope of this research is more focused on $B L U D$ in the health sector. So the conclusion might not be the same if the research object changed. Based on the results of the analysis and discussion, we can conclude that the current BLUD system only functions as a recording medium. There is no system to records in and out of inventory, including mechanism to request supplies via system. This can lead to a distribution of inventory to be easily manipulated and not transparent because supervision controls are inadequate. Internal control over inventory distribution expected to be better and have more control by designing information systems for inventory.

Moreover, according to the results carried out using a contingency theory perspective which applied in the PIECES Framework analysis, it can be concluded that the BLUD requires an Asset and Inventory System which integrated with the Accounting and Financial Reporting System. Also, several features are needed, but the current $B L U D$ system cannot provide it. For example, the current system does not have the automatic depreciation function, the automatic matching of expenditure realization data from procurement unit with $K I B$ data, etc. The proposed design for the information system composed is expected to be able to facilitate the demands needed.

Additionally, there is some limitation on this research. This research is only limited to $B L U D$ research objects that focus on the health sector, including the Health Office, Hospitals, and Health Centers. The design proposal of an information system for recording assets and inventories is based only on current conditions. From the limitations of this study, the suggestion for the development of further research could be an asset system which connects to the legal ownership document database system, e.g. Land Title Deed, Freehold Title, Proof of Motorized Vehicle Ownership, etc. Besides that, further study can also try to develop a system which can record the existence of an asset to the room level and will be automatically logged by using RFID when moving from one room to another can also improve internal control. Besides, future studies can use objects in another sector of BLUDs.

\section{References}

Adlar, L. R. (2014). Analisis Pengendalian Internal Aset Tetap Sistem Informasi Manajemen dan Akuntansi Barang Milik Negara: Studi Kasus Unit Organisasi Eselon 1 Markas Besar TNI.[Thesis]. Indonesia: University of Indonesia.

Badan Pemeriksa Keuangan Republik Indonesia. (2017). Laporan Hasil Pemeriksaan Atas Sistem Pengendalian Intern Tahun 2016.

Bentley, Lonnie D., \& Jeffrey L Whitten. (2007). Systems Analysis and Design for the Global Enterprise Seventh Edition. New York: McGraw-Hill.

Fiedler, F. E. and Chemers, M. M. (1974). Leadership and Effective Management, Glenview, IL: Scott, Foresman and Co.

Harrison, Walter T. (2013). Financial Accounting Ninth Edition. Pearson.

Jick, T. D. (1979). Mixing Qualitative and Quantitative Methods Triangulation in Action. Administrative Science Quarterly, 24, 602-611.

Moleong, L. (2002). Metodologi Penelitian Kualitatif. Bandung: PT. Remaja Rosdakarya.

Morse, J. M. (1991). Strategies for sampling. In J. M. Morse (Ed.), Qualitative nursing research: A contemporary dialogue. Newbury Park, CA: Sage. 
Peraturan Menteri Dalam Negeri Nomor 17 Tahun 2007 Tentang Pedoman Teknis Pengelolaan Barang Milik Daerah.

Romney, M. B., \& Steinbart, P. J. (2015). Accounting Information Systems Thirteenth Edition. Pearson.

Stake, R. E. (2006). Multiple Case Study Analysis. The Guilford Press.

Trochim, W. M., \& Donnelly, J. P. (2006). The Research Methods Knowledge Base. 3rd Edition, Atomic Dog, Cincinnati, $\mathrm{OH}$.

Yin, R. K. (2003). Case Study Research Design and Methods. 3rd Edition, Sage, Thousand Oaks.

Zain, M. Y. (2008). Minimizing The Problems of Enterprise Resource Planning (ERP) Implementation for Small to Medium Cigarette Company Through Framework for Applications of Systems Thingking (FAST). Media Informatika, 6.

Banyak Aset Hilang, DKI Bentuk Badan Pengelolaan Aset Daerah. (2017, Juni 20). Tempo.

Kalah di Pengadilan, DKI Kehilangan Aset Tanah 19,7 Hektare. (2017, Juli 4). Tempo. 